\title{
An Experimental Investigation on Hybrid Nanofluid with Vegetable Oils as a Cutting Fluid using Minimum Quantity Lubrication
}

\author{
Mr. Pratap R. Sonawane ${ }^{1 *},{ }^{2}$ Dr. Rahul B. Barjibhe \\ aPh.D. Scholar, SSBG College of Engg.and Technology, Bhusawal, Kavayitri \\ Bahinabai Chaudhari North Maharashtra University, Jalgaon, India. \\ ${ }^{2}$ Acedmic Dean, SSBG College of Engg. and Technology, Bhusawal, Kavayitri \\ Bahinabai Chaudhari North Maharashtra University, Jalgaon, India.
}

\begin{abstract}
Hard machining plays a vital role in traditional machining for high productivity and for complex jobs. In this type of machining cutting fluid have major factor property of cutting fluid to minimize the friction and to reduce the temperature at machining area. In traditional approach most of the time industries using mineral oils for lubrication or as cutting fluid in machining but due large amount of using of mineral oils large amount of oxidation happen which is toxic and harmful to workers. To overcome this effects experiment is done by using vegetable oil with addition of nanoparticles which enhanced the properties of cutting fluid. Experiment is done on Mild Steel with working pair of $\mathrm{Al}_{2} \mathrm{O}_{3}$ and $\mathrm{MoS}_{2}$ nanoparticles in palm oil. Output taken from this experiment in parameter's like cutting forces, surface temperature, tool temperature and surface roughness. From this method which gives better results than dry machining.
\end{abstract}

Keywords: Machining, Cutting parameters, MQL, Palm Oil, Cutting force, Surface roughness

\section{Introduction}

In machining operations like turning, grinding, boring, drilling, milling all having a output as maximum material removal rate with minimum utilization of cutting fluid as well as minimum tool wear. MQL method is always feasible than the dry and flood machining. In addition with nanoparticles system which gives increment in heat dissipation properties.

Paulo Davim et al [1] (2007) There are several attempts to minimize the use of lubricants in metallurgical processing from cost, ecology, and health problems. A wellestablished alternative to traditional flood lubrication is now minimum lubrication quantity (MQL). This article focuses on laboratory work with d different MQL levels during brass turning. The conversion was also done with flood lubrication and a comparison was made. The feed, cutting strength, other cuts and surface ruggedness have different parameters. Results of the analysis show that comparable findings with the flood lubricant can be achieved by using the MQL system correctly.

S. Khandekar et al [2] (2012) stated that the mixes of traditional washing fluids and nano particles were Nano-cutting fluids. Additional nano particles may change the strength of the weight, lubricating properties and the nano-slicing heat transfer coefficient. The present work creates nano cutting fluid by applying $1 \%$ of $\mathrm{Al} 2 \mathrm{O} 3$ nano particulate matter to the traditional cutting fluid. The weather property of this nano-cutting liquid is determined using the macroscopic touch angle method on a carbide tools handle. Traditional cutting fluids as well as the nano cutting tool, cutting speed, surface strength and chip thickness were compared experiments carried out. Machining of dry equipment was also carried out. Such investigations indicate that the nano-cutting fluid, as opposed to dry work and processing, decreases cutting power, the surface roughness of work pieces, tool wear, and chip thickness.

Kapil Gupta et al [3] (2015) Exploring the environmental responsibility for all 
environmentally conscious businesses is of utmost importance. Manufacturing must coordinate itself with specific stringent environmental standards to be sustainable internationally. The manufacturing sector in general aims at the efficiency and quality of the goods while maintaining a safe and healthy environment. It can only be accomplished by the implementation of innovative processing practices through the elimination of industrial processes by using modern and complementary technologies, renewable lubricants and lubrication procedures through machining, pollution prevention, active pollution management, and energy consumption elimination, etc. The key business suppliers in all other markets and industrial fields often concentrate on applying the strategies of total sustainability.

A. K. Sharmaet al [4] (2016)The cutting fluid plays a vital role as the work part surface and the cutting tool are cooled, the chips are withdrawn from the cutting area and a portion interface lubricated for all metal cuts operations. Misuse of fluid and inappropriate treatment practices can, however, have a negative effect on human health and the environment. In the near dry (NDM) or minimal quantity lubrication (MQL) areas, the investigators were late in using various techniques on coolant, minimizing the use of coolants by refining of compressed air mixture and cutting fluid in place of flood cooling. The MQL approach has proven its efficacy, as it fulfills the 'normal' criteria for processing.

M.S.Najiha et al [5] (2016) various articles on the advancement of lubrication methods in machining and the use of advanced nano fluids in machining were addressed. A brief review of the current literature on the environmental and health risks involved with metalworking fluids. The performance and draw backs of different technologies also included in the manufacturing parameters and variables.

N.A. C. Sidik et al [6] (2016) an comprehensive evaluation of nano fluid use in the machining phase was presented. Thanks to its capacity to boost thermal transfer and lubrication efficiency, nano fluid has gained considerable interest. To improve the performance and reliability of machine machines, Nano fluid MQL has shown to increase the coefficient of friction and tear. Nonetheless, it should be remembered that with multiple implementations a variety of $\mathrm{p}$ roblems must be identified and solved. Stability and manufacturing costs are two b ig impediments to nano fluid marketing. Meanwhile, recent studies have reported that hybrid nano fluid can be used to boost lubrication efficiency.

O. Gutnichenkoa et al [7] (2018) Experiments also shown that the influence of MQL has been accompanied by the machining efficiency of strong lubricant with cemented carbide devices. Nano platelet graphite $(\mathrm{GnP})$ shaped $(\sim 30 \mathrm{~nm})$, dispersed into a lubricant "ECOLUBRIC E200L" (0.2\% Vol.) based on vegetable oil and used for machining with MQL supported. The effects of cutting conditions on machining efficiency parameters such as strength, wear of tools, surface finish and vibrations have been observed. The findings show significant modifications in machine output, surface finishing and cycle processing performance with the MQL-assisted turning of Alloy 718 with GnP-modified oil.

Anshuman Dasa et al [8] (2019) The cutting performance of the AISI 4340 steel with four separate formulations of nano fluids using an MQL method, The comparative machinability measure is analyzed and improved during difficult turns of HSLA. Cutting with a minimum amount of lubrication (MQL) is analyzed and examined during hard turning using this article. The manufacturing of hardened steel AISI 4340 is measured in terms of mechanical properties such as cutting strength, wear of equipment (surfacing and crathering). It is also evaluated for the effect of $\mathrm{d}$ ifferent fluid characteristics such as thermal conductivity, viscosity, surface tension, and touch angle in terms of surface resistance, residual strength and micro-strength. The machinability is determined. In 
deionized mud, nano particles $\mathrm{ZnO}, \mathrm{CuO}, \mathrm{Fe} 2 \mathrm{O} 3$, and $\mathrm{Al} 2 \mathrm{O} 3$ were used to create four sets of nano fluids. $\mathrm{CuO}$ nano fluid had a superior behavior compared with these four nano fluids, followed by $\mathrm{ZnO}$ nano fluids when $\mathrm{Al} 2 \mathrm{O} 3$ nano fluid was the last nano fluid in the sample.

Roshan Lal et al [9] (2020) Discussed, vast quantities of cutting fluids to effectively monitor the lubrication phenomena require increasing efficiency demand in the machining sector. The use of lubricants/coolants in mechanical operations has made these processes more effective, but their processing is harmful to the environment. Therefore, environmental issues related to conventional fluids desperately involve environmentally safe cutting fluids. The MQL is an environmentally safe way of adding cutting fluids to system systems and is an easy working procedure. In the introduction, the introduction of Al2O3 nanomaterials to the simple fluid further increased surface strength lowered grinding power, and boosted the G-ratio. Improved superficial integrity under nanofluenza MQL technique will contribute to filling and polishing effects of nanoparticles together with good frictional behaviour.

Sarıkayac et al [10] (2020) its machinability is a difficulty to work with with other engineering super- Alliances, such as alloy 625. It requires extreme strength and stiffness, resistance to rust, and fair soiling properties. It is therefore important to use efficient methods of these strategies. We have studied the effect on behavior, the cutting temperature of products, minimal lubricating amounts (MQL), fluid nitrogen cryogens (LN2) and hybrid-CryoMQL. it's surfactant/topography and the morphology of the chip in a turning process to promote the machinability of alloy 625 using sustainable techniques. Experiments were carried out at 3 stages, set cup depth $(0.5 \mathrm{~mm})$ and feed frequencies $(0.12 \mathrm{~mm} / \mathrm{RC})(50,75$ and $100 \mathrm{~m} / \mathrm{min})$. As a result, the surface ruggedness of CryoMQL $(1.42 \mathrm{~m})$ increased by 24.82 percent relative to cryogenic cooling.

\section{Experimental work}

Experimental investigations are undertaken for Turning of mild steel material using palm oil with addition of nanoparticles cutting fluids. Different machining environments; MQL with different pair and dry are compared thoroughly. Following table 1 shows the cutting conditions and relevant details under consideration. A total of 28 experiments were performed considering the cutting speed, feed, and depth of cut kept constant at different cutting fluids as per Table 1.

Table 1.Experimental Conditions

\begin{tabular}{|c|c|c|}
\hline $\begin{array}{c}\text { Sr. } \\
\text { No. }\end{array}$ & Parameter & Description \\
\hline 1 & Material & Mild Steel \\
\hline 2 & Machine & Lathe \\
\hline 3 & Cutting Tool & Uncoated brazed carbide tool \\
\hline 4 & $\begin{array}{c}\text { Machining } \\
\text { Environment }\end{array}$ & MQL+ Nanoparticles ,Dry \\
\hline 5 & Cutting Fluids & Palm oil+ Nanoparticles \\
\hline 6 & Cutting speed $(\mathrm{Vc})(\mathrm{m} / \mathrm{min})$ & $90 \quad(\mathrm{~m} / \mathrm{min})$ \\
\hline 7 & Feed $(\mathrm{f})(\mathrm{mm} / \mathrm{rev})$ & $0.5(\mathrm{~mm} / \mathrm{rev})$ \\
\hline 8 & Depth of cut $(\mathrm{d})(\mathrm{mm})$ & $\mathrm{mm}$ \\
\hline
\end{tabular}




\subsection{Experimental setup and design of experiment:-}

MQL system with lathe machine which is used for the experimental investigation on mild steel as shown in fig 1 .

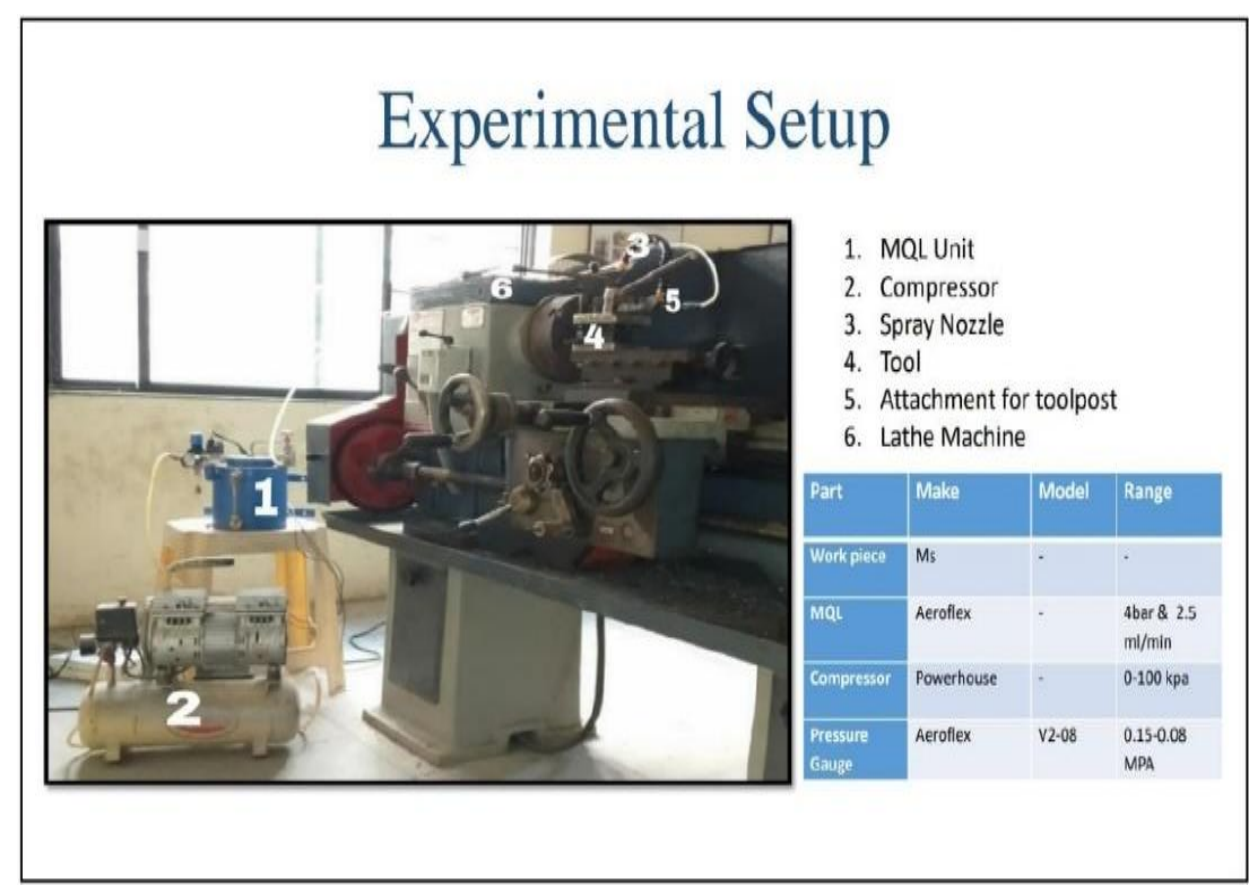

Figure1.The photographic view of the experimental set-up

\section{Results and discussion}

This results explain the measuring parameters for the current experimentation. Cutting force $(\mathrm{Fc})$, surface roughness $(\mathrm{Ra})$, and temperature $(\mathrm{T})$ are measured for the different machining environments under the varying cutting fluid application. The lathe tool dynamometer is used to measure the cuttingforces, while surface roughness and the temperature are measured with the portableroughness tester and infrared thermometer respectively. Three major cutting environments viz. dry, flood, MQL are used for the performance evaluation. Following tables, 2-7 show the with different oils under consideration.

Table2.Experimental conditions for lubrication For $1.25 \%$

\begin{tabular}{|c|c|c|c|}
\hline \multirow[t]{2}{*}{ Sr.No. } & \multirow[b]{2}{*}{ Compositions For Lubrication } & Speed & Feed \\
\hline & & RPM & $\mathrm{mm} / \mathrm{rev}$ \\
\hline 1 & 25\%ALUMINA +75\% Graphane +PALM OIL & 90 & 0.4 \\
\hline 2 & 50\%ALUMINA +50\% Graphane +PALM OIL & 90 & 0.4 \\
\hline 3 & 75\%ALUMINA +25\% Graphane +PALM OIL & 90 & 0.4 \\
\hline 4 & $100 \%$ Graphane +PALM OIL & 90 & 0.4 \\
\hline 5 & $100 \%$ ALUMINA +PALM OIL & 90 & 0.4 \\
\hline 6 & For Dry Machining & 90 & 0.4 \\
\hline 7 & For Palm OIL Lubrication & 90 & 0.4 \\
\hline
\end{tabular}




\subsection{Performance evaluation of Feed Force}

This graph describes the performance evaluation of feed force under consideration.

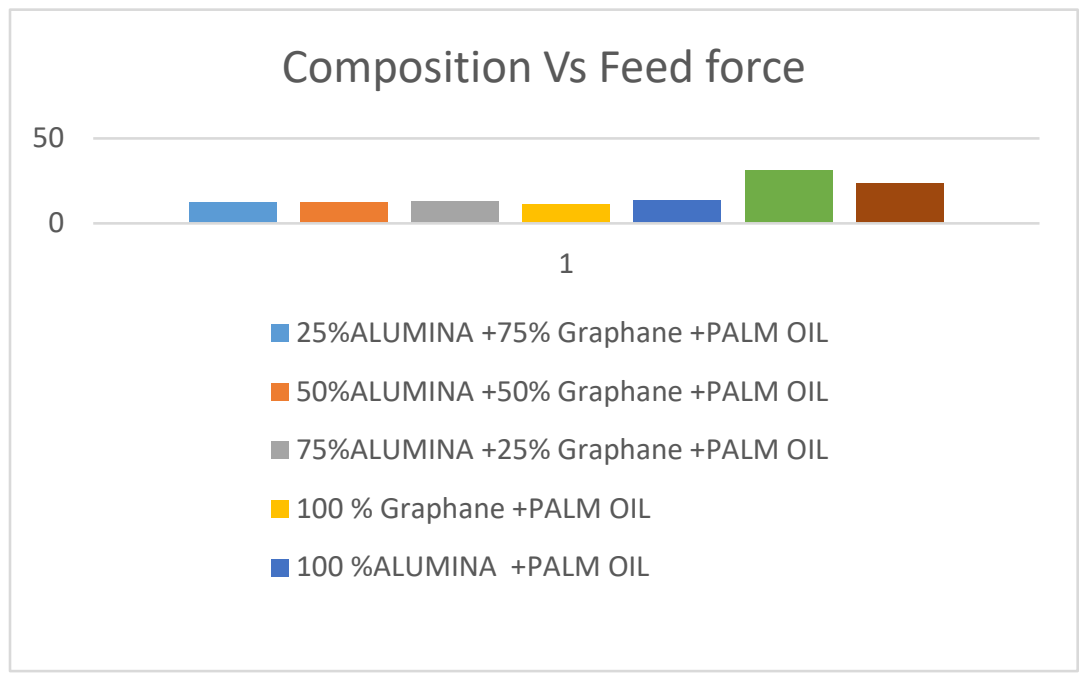

Figure 2 shows the effect of varying cutting oil conditions on feed force under the different machining conditions. It is shows that palm oil reduces the feed forces as compare to dry machining. By addition to graphene which gives better results with the help of MQL set up.

Figure2.Variation of Feed force at different cutting conditions

\subsection{Performance evaluation of Thrust force.}

The graph shows performance evaluation of Thrust Force is presented here.

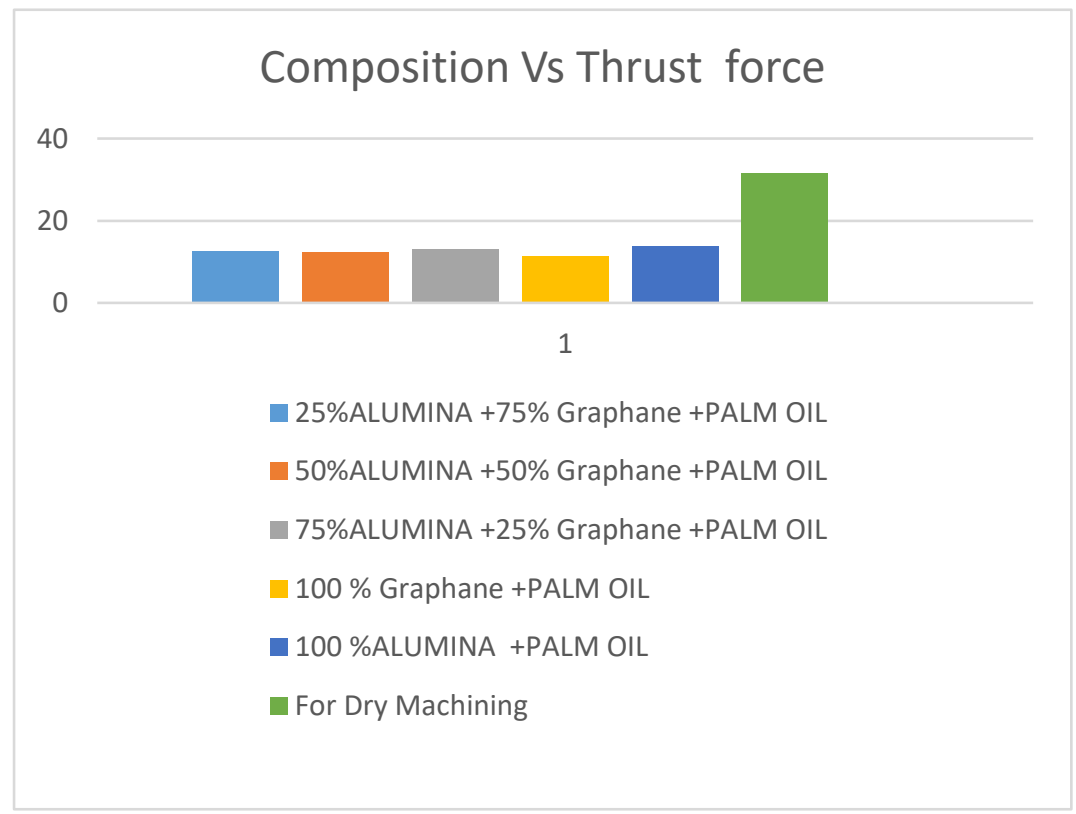

Figure3.Variation of Thrust force at different cutting conditions

Figure 3 shows the effect of varying cutting oil conditions on cutting force under the different machining conditions. It is shows that palm oil reduces the thrust forces as compare to dry machining. By addition to graphene which gives better results as well as $25 \%$ alumina and 75 $\%$ graphene also gives good results with the help of MQL set up. 


\subsection{Performance evaluation of cutting forces.}

The graph shows performance evaluation of cutting forces is presented here.

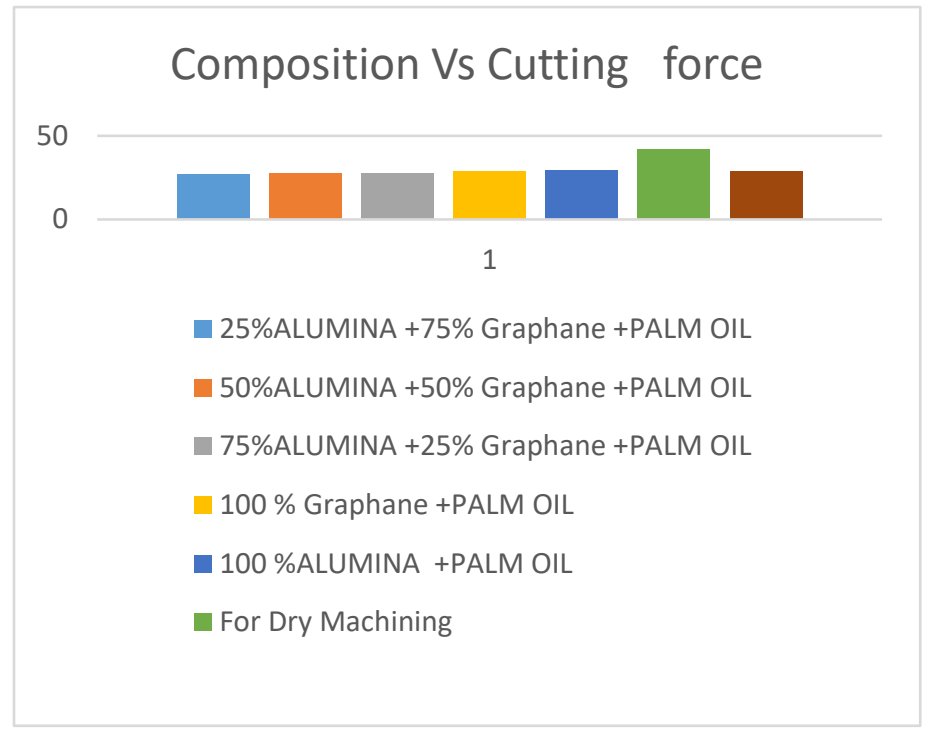

Figure4.Variation of Cutting Forces at different cutting conditions

Figure 4 shows the effect of varying cutting oil conditions on cutting force under the different machining conditions. It is shows that palm oil reduces the thrust forces as compare to dry machining. By addition to graphene which gives nearly same results for $25 \%$ alumina and $75 \%$ graphene, $25 \%$ alumina and $75 \%$ graphene, $25 \%$ alumina and $75 \%$ graphene and $100 \%$ graphene also gives good results with the help of MQL set up.

\subsection{Performance evaluation of Temp of Tool after turning operation.}

This subsection describes the performance evaluation for power consumption under consideration.

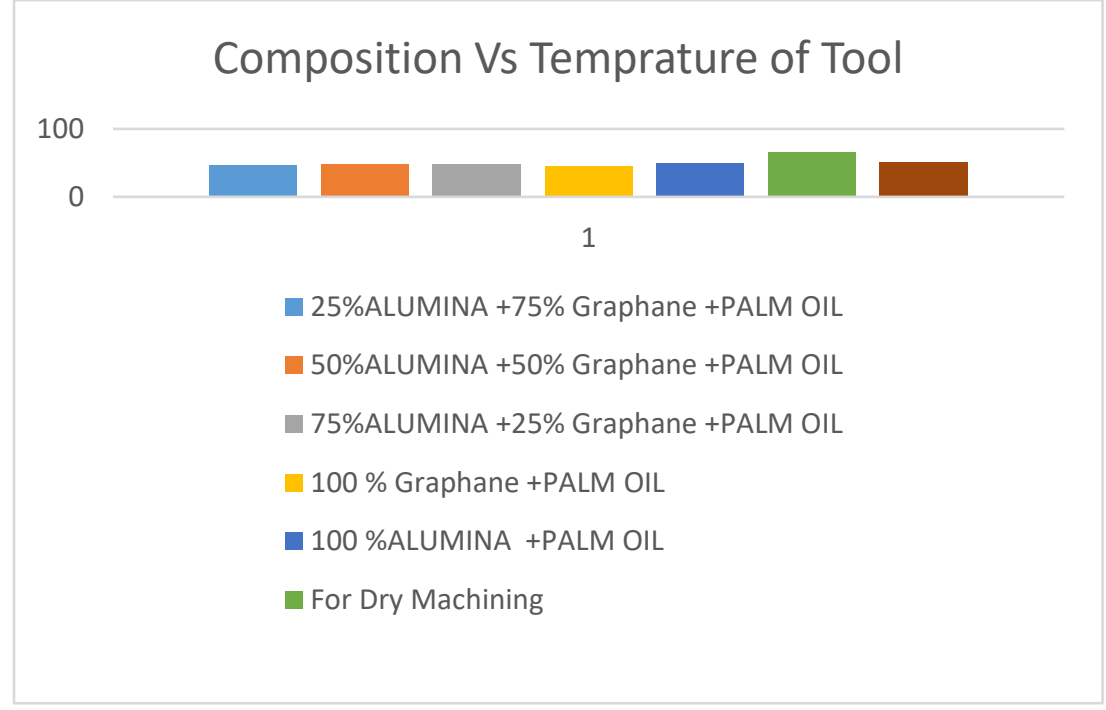

Figure5.Variation of Temperature of tool after turning at different cutting conditions

Figure 5 shows the effect of varying cutting oil conditions on Temperature of tool under the different machining conditions. It is shows that palm oil reduces the temperature of tool as compare to dry machining. By addition to $100 \%$ graphene which gives better results as well as $25 \%$ alumina and $75 \%$ graphene also gives good results with the help of MQL set up. 


\subsection{Performance evaluation of Temperature of cutting fluid after turning operation.}

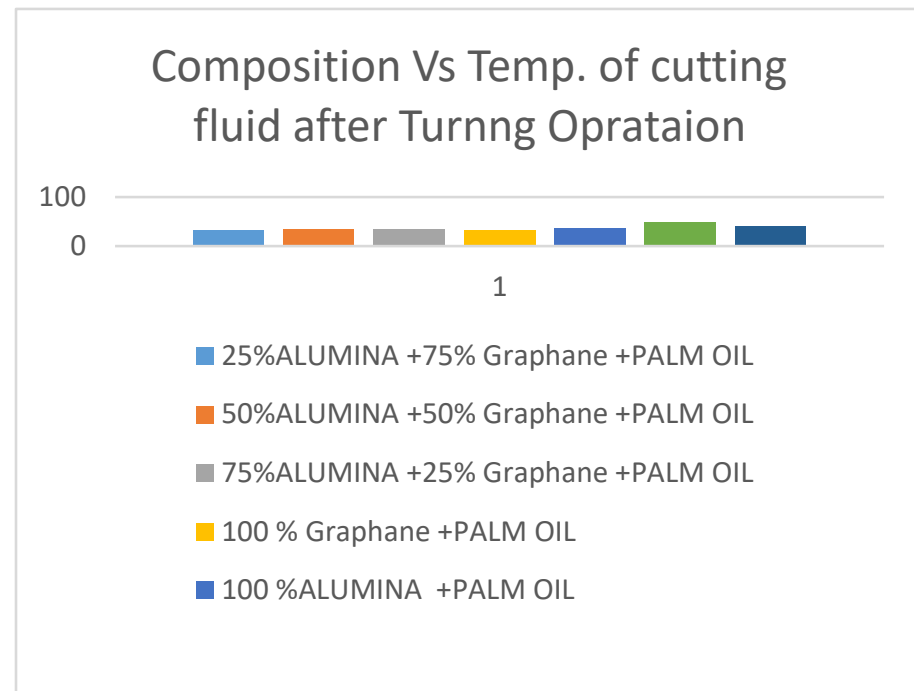

Figure 6 shows the effect of varying cutting oil conditions on Temperature of tool under the different machining conditions. It is shows that palm oil reduces the temperature of tool as compare to dry machining. By addition to 100 $\%$ graphene which gives better results as well as $25 \%$ alumina and $75 \%$ graphene also gives good results with the help of MQL set up.

Figure 6 .Variation of Temperature of cutting fluid after turning at different cutting conditions

\subsection{Performance evaluation of Surface Roughness after turning operation.}

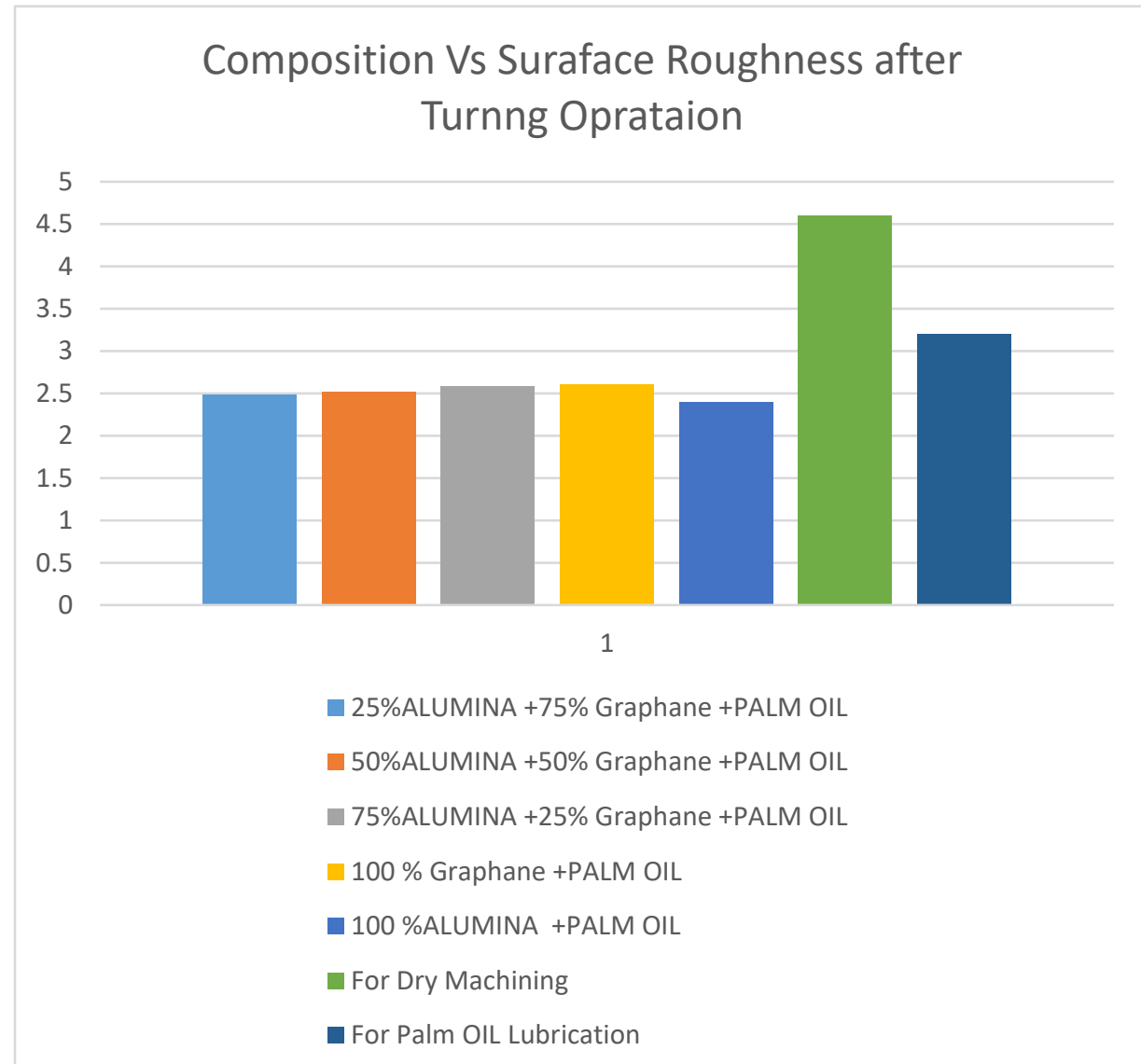

Figure 7.Variation of Temperature of cutting fluid after turning at different cutting conditions

Figure 7 shows the effect of varying cutting oil conditions on Temperature of cutting fluid under the different machining conditions. It is shows that palm oil reduces the temperature of cutting fluid as compare to dry machining. By addition to $100 \%$ alumina which gives better results as well as $25 \%$ alumina and 75 $\%$ graphene also gives good results with the help of MQL set up. 
3.8 Performance evaluation of Forces after turning operation.

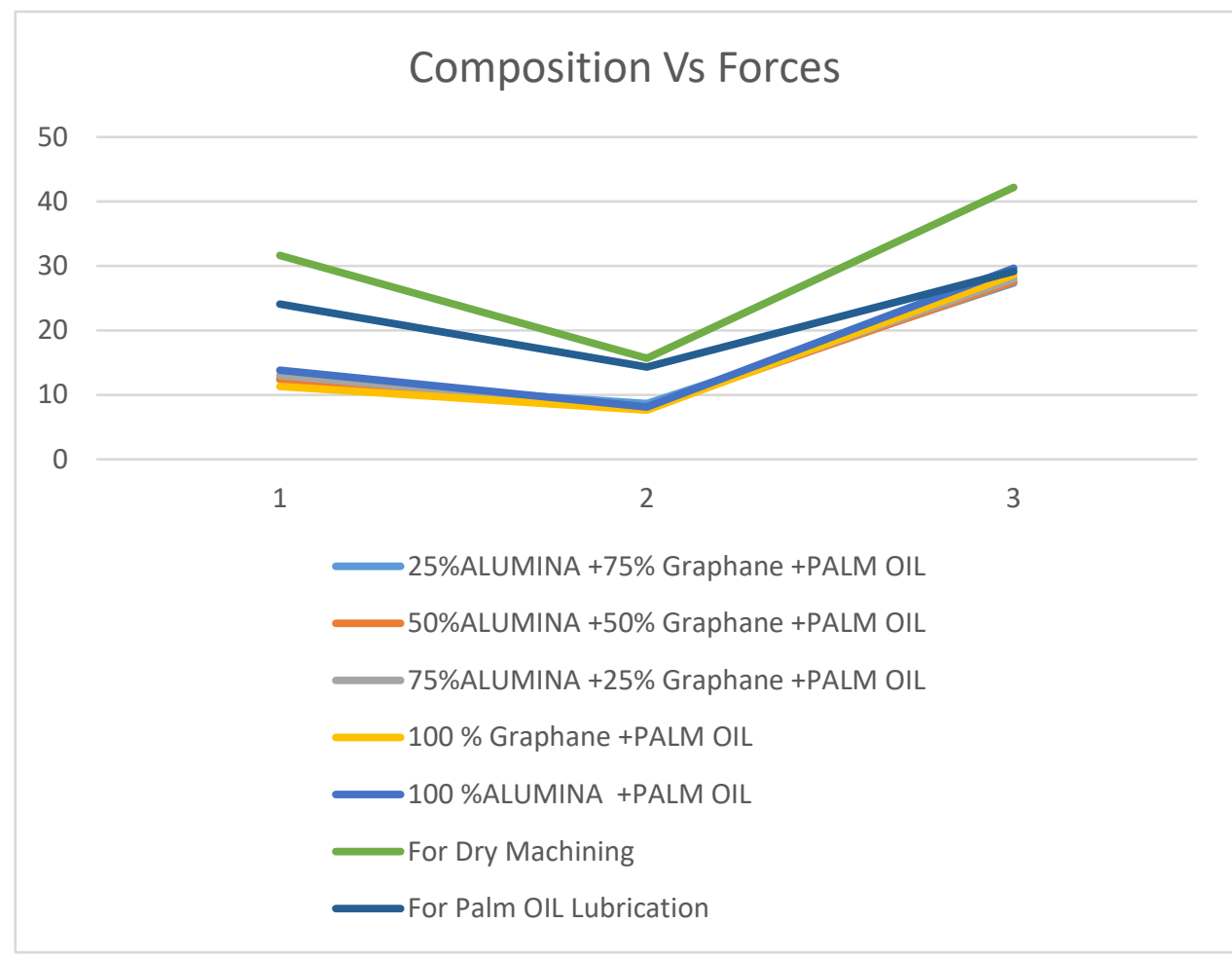

Figure 7 shows the effect of varying cutting oil conditions on cutting forces under the different machining conditions. It is shows that cutting forces are minimize or same for $25 \%$ alumina and $75 \%$ graphene, $25 \%$ alumina and 75 $\%$ graphene, $25 \%$ alumina and $75 \%$ graphene and $100 \%$ graphene the fluid as compare to dry machining with the help of MQL set up.

Figure 8 .Variation of Temperature of cutting fluid after turning at different cutting conditions

\section{Conclusions}

The present research work is carried out to evaluate the performance of various vegetable-based cutting fluids under varying cutting environments concerning the measuring parameters; cutting force, surface roughness, temperature, and power consumption. Based on the comprehensive experimental investigation following conclusions and remarks could be drawn:

- Minimum quantity lubrication shows improved characteristics in all aspects. The cutting forces, temperature, surface roughness, and power consumption found reduced under the application of MQL as compared to the dry and flood lubrication technique. MQL is also useful in the consumption of the cutting fluid

- The vegetable oils under MQL shows significant performance improvement than that of dry and palm oil as cutting fluid.

- Palm oil with $50 \%$ alumina and graphene which results shows having minimum cutting forces with respect to other composition.

- Palm oil with $100 \%$ graphene shows temperature of tool tip is giving minimum as compare to others. 
- With respect to composition of palm oil and nano particles for roughness value for $100 \%$ alumina giving better result than others composition.

- The overall observations under all machining environments show that the depth of cut and feed rate as constant graphene and alumina gives better results but by hybridization of palm oil ,graphene and alumina at $25 \%$ alumina and $75 \%$ of graphene with base fluid as palm oil for $1.25 \%$ of weight of total palm oil in terms of cutting forces, roughness value and temperatures of tool tip and cutting fluid after turning operation completed 


\section{References}

[1] J. Paulo Davim, P. S. Sreejith, and J. Silva, "Turning of Brasses Using Minimum Quantity of Lubricant (MQL) and Flooded Lubricant Conditions”, Materials and Manufacturing Processes, 22: 45-50, 2007.

[2] S. Khandekar, M. Ravi Sankar, V. Agnihotri, and J. Ramkumar, "Nano-Cutting Fluid for Enhancement of Metal Cutting Performance” Materials and Manufacturing Processes, 27: 963-967, 2012.

[3]Kapil Gupta R.F. Laubscher J. Paulo Davim3 N.K. Jain, "Recent developments in sustainable manufacturing of gears: a review" PII: S09596526(15)01373

[4]Anuj Kumar Sharma, Arun Kumar Tiwari , Amit Rai Dixit Effects of Min imum Quantity Lubrication (MQL) in machining processes using conventional and nanofluid based cutting fluids: A comprehensive review Journal of Cleaner Production 127 (2016)

[5]M.S. Najiha, M.M. Rahman, A.R. Yusoff, "Environmentalimpacts and hazard sassociated with metal working fluids and recent advances in the sustainable systems: A review" Contents lists available at Science Direct journal homepage: www.elsevier.com/locate/rser Renewable and Sustainable Energy Reviews ELSEVIER

[6] Nor Azwadi Che Sidik, Syahrullail Samion, Javad Ghaderian, Muhammad Noor Afiq Witri Muhammad Yazid , "Recent progress on the application of nanofluids in minimum quantity lubrication machining: A review" International Journal of Heat and Mass Transfer journal homepage: www.elsevier.com/locate/ijhmt Faculty of Mechanical Engineering, Universitiy Teknologi Malaysia, 81310 ELSEVIER

[7] Oleksandr Gutnichenkoa, Volodymyr Bushlya, Sverker Bihagen, Jan-Eric Ståhl, "Influence of GnP additive to vegetable oil on machining performance when MQL-assisted turning Alloy 718”, ELSEVIER, COSS MARK, PROCEDIA MANUFACURING 8th Swed ish Production Symposium, SPS 2018, 16-18 May 2018.

[8] Anshuman Dasa, Omprakash Pradhanb, Saroj Kumar Patelb, Sudhansu Ranjan Dasc, Bibhuti Bhusan Biswala, "Performance appraisal of various nanofluids during hard machining of AISI4340 steel" Contents lists available at Science Direct Journal of Manufacturing Processes.

[9] Roshan Lal Virdi, Sukhpal Singh Chatha, Hazoor Singh, "Performance Evaluation of Inconel 718 under vegetable oils based nanofluids using Minimum Quantity Lubrication Grinding”journal homepage: www.elsevier.com/locate/matpr, ELSEVIER, MATERIALS TODAY PROCEDINGS.

[10] C, a` grı Vakkas Yıld ırım, Turgay Kıvak, Murat Sarıayac, S, enol S, irin Evaluation of tool wear, surface roughness/topography and chip morphology when machining of $\mathrm{Ni}$-based alloy 625 under MQL, cryogenic cooling and CryoMQL Available online at www.sciencedirect.coM ELSEVIER. 